\title{
CÁC YẾU TỐ ẢNH HƯởNG ĐẾN Ý ĐỊNH MUA THỰC PHẨM HŨ̉U CƠ CỦA NGƯỜI TIÊU DÙNG THÀNH PHỐ HỒ CHÍ MINH DỰA TRÊN MÔ HÌNH S-O-R
}

\author{
LÊ HỒNG SƠN ${ }^{1}$, PHẠM XUÂN KIÊN ${ }^{2}$ \\ ${ }^{1}$ Trường Đại học Bách Khoa, Đại học Quốc Gia Thành phố Hồ Chỉ Minh, \\ ${ }^{2}$ Trường Đại học Công nghiệp Thành phố Hồ Chí Minh; \\ phamxuankien@iuh.edu.vn
}

Tóm tắt. Nghiên cứu này dựa trên mô hình cải tiến (S-O-R) nhằm nhận dạng và đo lường ảnh hưởng của các yếu tố là hàm lượng dinh dưỡng, hàm lượng tự nhiên, bảo vệ hệ sỉnh thái, hấp dẫn giác quan, giá, thái độ vị lợi và thái độ hưởng thụ đối với ý định mua thực phẩm hữu cơ của người tiêu dùng Tp.Hồ Chí Minh. Dựa trên kiểm nghiệm mô hình cấu trúc với bộ dữ liệu thu thập từ 289 người tiêu dùng; kết quả nghiên cứu cho thấy thái độ hưởng thụ và thái độ vị lợi có tác động tích cực và trực tiếp đến ý định mua của người tiêu dùng, còn các yếu tố hàm lượng dinh dưỡng, hàm lượng tự nhiên, bảo vệ hệ sinh thái, hấp dẫn giác quan có tác động tích cực và giá có tác động tiêu cực lên thái độ vị lợi và thái độ hưởng thụ. Nghiên cứu này giúp cho những người làm tiếp thị và thực hiện chính sách hiểu rõ phải làm thế nào để người tiêu dùng hình thành ý định mua thực phẩm hữu cơ.

Từ khóa. Ý định mua, thực phẩm hữu cơ, mô hình S-O-R.

\section{FACTORS INFLUENCING HO CHI MINH CITY CONSUMERS' INTENTION TO BUY ORGANIC FOODS BASED ON THE S-O-R MODEL}

\begin{abstract}
This study is based on the modified Stimulus-Organism-Response (S-O-R) model to identify and measure the impact of Nutritional content, Natural content, Ecological welfare, Sensory appeal, Price, Utilitarian attitude and Hedonic attitude on Ho Chi Minh City consumers' intention to buy organic foods. The research is based on analyzing strutural equation modelling with data were collected from 289 consumers; the results show that Hedonic attitude and Utilitarian attitude have positive impacts on customers' intention to buy organic foods, while Nutritional content, Natural content, Ecological welfare, Sensory appeal have positive impacts and Price has a negative impact on Hedonic attitude and Utilitarian attitude. This study provides marketers and policy makers to understand how consumers form their intention to buy organic foods.
\end{abstract}

Keyword. Intention to buy, Organic foods, S-O-R model.

\section{GIỚI THIẸU}

Tốc độ phát triển kinh tế tăng dẫn tới gia tăng nhu cầu về rau hữu cơ vì lí do sức khỏe, đặc biệt với những gia đình có thu nhập cao [1]. Nhu cầu về các sản phẩm hữu cơ hoặc các sản phẩm hữu cơ gần đây đã nhận được sự quan tâm của người tiêu dùng do mối quan tâm ngày càng tăng của họ về các vấn đề môi trường, giá trị dinh dưỡng của thực phẩm và các vấn đề sức khoẻ [2]. Chất lượng và sự an toàn của thực phẩm thu hút sự quan tâm của người tiêu dùng và ảnh hưởng đến hành vi mua hàng [3].

Theo Nielsen [4], vấn đề sức khỏe vẫn tiếp tục nằm trong 5 mối bận tâm lớn nhất của người tiêu dùng Việt Nam. Ở Việt Nam, trong những năm gần đây nền nông nghiệp đã phát triển mạnh mẽ nhất là trong nghiên cứu, triển khai các ứng dụng tiến bộ khoa học kỹ thuật vào sản xuất và chế biến nông sản thực phẩm. Tuy nhiên, sản phẩm nông sản Việt Nam kém cạnh tranh về chất lượng, mẫu mã, nhiều loại sản phẩm chưa đạt vệ sinh an toàn thực phẩm. Thị trường các sản phẩm hữu cơ của Lào và Việt Nam đang ở giai đoạn phát triển ban đầu, nhưng đang mở rộng nhanh chóng vì những lo ngại về an toàn thực phẩm và sự thừa nhận thâm hụt thị trường ngày càng tăng ở các nước láng giềng như Thái Lan [5]. 
Thị trường thực phẩm hữu cơ toàn cầu tiếp tục phát triển trên toàn thế giới. Thực phẩm hữu cơ và đồ uống là một phân khúc thị trường phát triển nhanh chóng trong ngành công nghiệp thực phẩm toàn cầu. Hơn nữa, các báo cáo gần đây cho thấy nông nghiệp hữu cơ là một hệ thống trang trại tiên tiến cân bằng các mục tiêu bền vững và sẽ có tầm quan trọng ngày càng tăng trong an ninh lương thực và an ninh hệ sinh thái toàn cầu. Nhu cầu cao về thực phẩm hữu cơ ở Châu Ầu và Bắc Mỹ đã dẫn đến việc nhập khẩu thực phẩm hữu cơ từ những trang trại lớn ở các nước kém phát triển. Giá cao cho các loại thực phẩm xuất khẩu có thể mang lại lợi ích cho nông dân [6].

Hiện nay, trên thế giới đã có một số khung lý thuyết được sử dụng để nghiên cứu về việc tiêu dùng thực phẩm hữu cơ là các mô hình "hành vi- thái độ" như lý thuyết hành động hợp lý (TRA) và lý thuyết về hành vi hoạch định $(\mathrm{TPB})[7,8,9]$. Một trong những giả định chính của TRA và TPB là người tiêu dùng đều có lý do trong quá trình ra quyết định và hành động của họ, các phương pháp về nhận thức có thể được sử dụng để dự đoán các hành vi $[10,11]$. Tuy nhiên, việc bổ sung các biến số cảm xúc đã được đề xuất như là một sự mở rộng có ích của lý thuyết [12]. Mô hình Stimulus-Organism-Response (S-O-R) của Mehrabian và Russell [13] cho phép các nhà nghiên cứu kiểm tra cả ảnh hưởng nhận thức lẫn cảm xúc đối với hành vi. Mô hình S-O-R cơ bản bao gồm ba yếu tố là kích thích, tổ chức và phản ứng (hồi đáp); trong đó, yếu tố kích thích thường được coi là ở bên ngoài, yếu tố tổ chức thường đề cập đến các trạng thái bên trong phát sinh từ các kích thích môi trường bên ngoài và yếu tố phản ứng (hồi đáp) là kết quả cuối cùng được phân loại là hành vi tiếp cận hoặc hành vi tránh né. Tuy nhiên, cho đến nay, chưa có nghiên cứu nào sử dụng mô hình $\mathrm{S}-\mathrm{O}-\mathrm{R}$ để giải thích hành vi mua hàng của người tiêu dùng về thực phẩm hữu cơ [15].

Trong nghiên cứu này, mô hình S-O-R của Mehrabian và Russell [13] được điều chỉnh bằng cách sử dụng nhận thức của người tiêu dùng về các thuộc tính thực phẩm hữu cơ như yếu tố kích thích, thái độ vị lợi, thái độ hưởng thụ như yếu tố tổ chức và ý định hành vi như yếu tố phản ứng.

Các nghiên cứu về dự định mua thực phẩm hữu cơ của người tiêu dùng tại Việt Nam cho tới nay chủ yếu dựa trên lý thuyết hành vi hoạch định $(\mathrm{TBP})$ và chưa có nghiên cứu nào sử dụng mô hình $\mathrm{S}-\mathrm{O}-\mathrm{R}$. Trước bối cảnh đó, với mong muốn tìm hiểu về các yếu tố ảnh hưởng tới ý định mua thực phẩm hữu cơ trên địa bàn thành phố Hồ Chí Minh dựa trên một khung lý thuyết mới, nên đề tài "Các yếu tố ảnh hưởng đến ý định mua thực phẩm hữu cơ của người tiêu dùng Thành Phố Hồ Chí Minh dựa trên mô hình S-O-R" được hình thành.

\section{CƠ SỞ LÝ THUYÊT VÀ CÁC GIẢ THUYẾT}

\subsection{Các khái niệm nghiên cứu}

Thực phẩm hữu co (Organic Foods): Theo Chen [15], thực phẩm hữu cơ là thực phẩm không biến đổi gen và được sản xuất theo cách tự nhiên và đặc biệt không sử dụng các hóa chất tổng hợp như thuốc trừ sâu. Còn theo Essoussi và Zahaf [16], thực phẩm hữu cơ được nuôi trồng và xử lý mà không sử dụng phân bón, thuốc trừ sâu, những chất tăng trưởng, phụ gia thức ẳn chăn nuôi và biến đổi gen để đảm bảo tính toàn vẹn của thực phẩm tới người sử dụng cuối cùng.

Ý định thực hiện hành vi (Behavioral intention): Theo Ajzen [17] thì một hành vi có thể được dự đoán bởi các ý định trước đó. Quan điểm của lý thuyết hành vi hoạch định cho rằng ý định và khuynh hướng cá nhân là chỉ báo dự đoán hành vi. Ý định được thừa nhận là động cơ dẫn đến hành vi, là dấu hiệu của mức độ sẵn sàng mua. Như vậy, nhân tố quan trọng nhất ảnh hưởng lên hành vi là ý định hay khuynh hướng hành vi. Các ý định được giả định để nắm bắt các yếu tố động lực ảnh hưởng đến hành vi; Chúng là dấu hiệu cho thấy người ta sẵn sàng cố gắng như thế nào, về nỗ lực của họ mà họ đang có kế hoạch sử dụng, để thực hiện hành vi đó. Theo nguyên tắc chung, ý định tham gia vào hành vi mạnh mẽ hơn thì khả năng hoạt động của nó càng cao. Tuy nhiên, phải rõ ràng rằng một ý định hành vi có thể chỉ biểu hiện trong hành vi chỉ khi hành vi đang được đề cập được kiểm soát theo ý chí.

Hàm lượng dinh dưỡng (Nutritional content): Hàm lượng dinh dưỡng của thực phẩm là tất cả các chất có trong nó giúp người sử dụng duy trì sức khoẻ. Hàm lượng dinh dưỡng của thực phẩm là bao gồm những chất dinh dưỡng cần thiết cho cơ thể sống, đó là các chất sinh ra năng lượng bao gồm protein, lipit, gluxit và các chất không sinh năng lượng bao gồm các vitamin, các chất khoáng và nước [18]. 


\section{CỦA NGƯỜI TIÊU DÙNG THÀNH PHỐ HỒ CHÍ MINH DỬA TRÊN MÔ HİNH S-O-R}

Hàm lượng tự nhiên (Natural content): Hàm lượng tự nhiên của thực phẩm đó là thực phẩm đó không có màu nhân tạo hoặc các chất phụ gia thực phẩm được thêm vào trong quá trình chế biến, do đó duy trì được bản chất ban đầu của nguyên liệu và sản xuất mà không có điều kiện gia công quá mức. Người tiêu dùng thực phẩm hữu cơ có xu thế hướng về việc sử dụng các nhãn hiệu "không có thuốc trừ sâu" , "không có hóc môn", "không có hóa chất", "không ô nhiễm", "không kháng sinh", "không có GMO"; các loại thực phẩm như vậy được gọi là "tự nhiên" [16].

Bảo vệ hệ sinh thái (Ecological Welfare): Bảo vệ tự nhiên, bảo vệ động vật hoặc các hành động bảo vệ thiên nhiên khác đều được xem là hướng đến việc cải thiện phúc lợi sinh thái, ví dụ: "Điều quan trọng nhất đối với tôi là động vật không bị ảnh hưởng" [19]. Bảo vệ động vật là một cấu trúc đa cấp, nó được sử dụng bởi những người tiêu dùng như là một chỉ số về chất lượng thực phẩm, an toàn thực phẩm và cách đối xử với vật nuôi và gia súc [20]. Sự nhạy cảm về môi trường và việc bảo vệ động vật cũng đã được tìm thấy để thúc đẩy việc mua các sản phẩm hữu cơ [21].

Hấp dẫn giác quan (Sensory Appeal): Sự hấp dẫn giác quan liên quan đến việc tiêu thụ thực phẩm làm cho người tiêu dùng cảm thấy tốt về mặt thể chất và cảm xúc, cũng như để hưởng thụ hành vi ăn. Tính quen thuộc là một yếu tố quan trọng trong việc này, hàm ý rằng thực phẩm không chỉ được xem để nếm và ngửi tốt hơn, mà nó còn được hoạt động như một loại “thực phẩm thoải mái” gợi lên cảm giác an toàn và tính truyền thống [22].

Giá (Price): Giá là một khoản phí tổn kinh tế mà một người bỏ ra để nhận được hàng hóa hay dịch vụ [23]. Theo học thuyết kinh tế, người tiêu dùng thường rất nhạy cảm với giá bởi họ có xu hướng tìm kiếm những sản phẩm có giá thấp hơn và họ mong muốn có được sự thỏa mãn thông qua việc so sánh các sản phẩm khác nhau [24]. Theo lý thuyết kinh tế truyền thống, giá được xem như một sự hy sinh về tiền tệ cần thiết để mua hàng. Do đó, giá cao hơn sẽ nâng cao nhận thức về chi phí kinh tế và do đó ảnh hưởng tiêu cực đến việc đánh giá sản phẩm và các ý định mua hàng [25].

Thái độ vị lọ̣i (Utilitarian attitude) và thái độ hưởng thụ (Hedonic attitide): Theo Batra và Ahtola [26] thì thái độ vị lợi liên quan đến khía cạnh chức năng, không có yếu tố cảm giác và liên quan đến các kì vọng về kết quả, còn thái độ hưởng thụ liên quan đến khía cạnh cảm giác. Còn theo định nghĩa của Voss [27], yếu tố thái độ vị lợi được thể hiện bởi sản phẩm và tyu tố thái độ hưởng thụ là kết quả có được từ cảm giác và được lẩy từ kinh nghiệm sử dụng sản phẩm. Nghiên cứu về các thành phần của thái độ hưởng thụ và vị lợi đã được đề xuất trong nhiều lĩnh vực như xã hội học, tâm lý học, kinh tế và tiếp thị để hiểu rõ hơn về động cơ và/hoặc thái độ của người tiêu dùng [28].

\subsection{Các giả thuyết}

Hàm lượng dinh dưỡng và hàm lượng tự nhiên đối với thái độ vị lọi và thái độ hưởng thụ: Sức khỏe nói chung được đồng ý là động lực chính cho việc mua thực phẩm hữu cơ. Trong những nghiền cứu trước, tính chất có lợi cho sức khỏe của thực phẩm hữu cơ đã được tìm thấy là lý do thường được đề cập nhiều nhất giải thích tại sao người tiêu dùng lựa chọn thực phẩm hữu cơ [29]. Mặc dù nó gây nên tranh cãi liệu thực phẩm hữu cơ có thực sự bổ dưỡng hơn hay không so với thực phẩm thông thường, một số nghiên cứu cho thấy người tiêu dùng đã tin như thế [30]. Davies et al. [31] cho biết thực phẩm hữu cơ được trồng một cách tự nhiên khiến người tiêu dùng tin rằng thực phẩm hữu cơ có lợi cho sức khỏe hơn thực phẩm thông thường. Những niềm tin như vậy liên quan đến nhận thức về an toàn của người tiêu dùng về thực phẩm hữu cơ. Mặc dù không có nhà nghiên cứu nào trước đây nghiên cứu các thuộc tính của sản phẩm thực phẩm hữu cơ ảnh hưởng đến hai khía cạnh của thái độ là thuộc tính sức khỏe và an toàn của thực phẩm hữu cơ có liên quan đến cả thái độ thực tế và hưởng thụ. Một số nghiên cứu về giá trị của người tiêu dùng và động lực của hành vi mua thực phẩm hữu cơ đã lưu ý rằng sức khoẻ và các thuộc tính liên quan đến an toàn (ít phụ gia, ít hóa chất, ít hơn thuốc trừ sâu, sản xuất tự nhiên) liên quan đến các kết quả chức năng [32], nhưng các thuộc tính như vậy cũng thúc đẩy người tiêu dùng cảm thây thoải mái hay trải nghiệm thú vị [29]. Vì vậy, điều này là hợp lý để có thể tin rằng các thuộc tính hàm lượng dinh dưỡng và hàm lượng tự nhiên liên quan đến thái độ hưởng thụ cũng như thái độ vị lợi . Theo đó, các giả thuyết $\mathrm{H} 1 \mathrm{a}, \mathrm{H} 1 \mathrm{~b}$ và $\mathrm{H} 2 \mathrm{a}, \mathrm{H} 2 \mathrm{~b}$ có thể được phát biểu như sau:

H1a: Nhận thức của nguời tiêu dùng về thuộc tính Hàm lự̛ng dinh dữ̛ng có một tác động tích cực đáng kể đối với Thái độ vị lợi hướng tới việc mua thực phẩm hũu co:

H1b: Nhận thức của người tiêu dùng về thuộc tính Hàm luợng dinh duõng có một tác động tích cưc đáng kể đối với Thái độ huởng thụ hướng tới viẹc mua thực phẩm hữu co: 
H2a: Nhận thức của người tiêu dùng về thuộc tính Hàm lượng tư nhiên có một tác động tích cực đáng kể đối với Thái độ vị lợi hướng tới việc mua thực phẩm hũu co:

H2b: Nhận thức của người tiêu dùng về thuộc tính Hàm luợng tự nhiên có một tác động tích cưcc đáng kể đối với Thái độ huơơng thu hướng tới việc mua thưc phẩm hũu co.

Bảo vệ hệ sinh thái đối với thái độ vị lọ̣i và thái độ hưởng thụ: Các thuộc tính sản phẩm liên quan đến phúc lợi sinh thái (tức là, bảo vệ mồi trường và sự an toàn động vật) cũng thúc đẩy người tiêu dùng chọn thực phẩm hữu cơ [29]. Lea và Worsley [30] đã phát hiện ra rằng thực phẩm hữu cơ được xem là thân thiện với môi trường hơn so với thực phẩm thông thường. Harper và Makatouni [20] nói rằng thực phẩm hữu cơ được coi là tốt cho động vật bởi vì không sử dụng các hoóc môn, kháng sinh, và thuốc trừ sâu trong quá trình nuôi. Như vậy, nghiên cứu này đã được chứng minh rằng mối quan tâm đối với môi trường dẫn đến thái độ tiêu dùng thuận lợi [21]. Tuy nhiên, mối quan ngai về sự an toàn động vật đã ít ảnh hưởng hơn đến việc người tiêu dùng mua thực phẩm hữu cơ hơn mối bận tâm về sức khỏe và môi trường [33].

Thuộc tính bảo vệ hệ sinh thái của thực phẩm hữu cơ có thể liên quan cả thái độ vị lợi và thái độ hưởng thụ. Thuộc tính bảo vệ môi trường và sự an toàn động vật dường như là một dấu hiệu của chất lượng sản phẩm hay an toàn thực phẩm vì người tiêu dùng cảm nhận thực phẩm hữu cơ được nuôi trồng không có thuốc trừ sâu, thuốc kích thích, thuốc tăng trưởng và thuốc kháng sinh [20]. Do đó, đánh giá của người tiêu dùng có thể được thúc đẩy bởi các giá trị chức năng [32]. Tuy nhiên, điều này thuộc tính cũng có thể tạo ra sự hài lòng cảm xúc. Một số nghiên cứu cho rằng hệ thống giá trị của người tiêu dùng ảnh hưởng đến thái độ và các giá trị của chủ nghĩa phổ quát, lòng nhân từ và lòng vị tha (tập trung vào sự an toàn của người khác) ảnh hưởng đến người tiêu dùng thực phẩm hữu cơ $[20,30]$. Về vấn đề này, người tiêu dùng có thể sẽ cảm thấy vui hoặc thỏa mãn vì họ tin rằng việc mua thực phẩm hữu cơ góp phần vào môi trường và sự khỏe mạnh của động vật $[29,34]$. Vì vậy, giả định rằng thuộc tính bảo vệ hệ sinh thái của thực phẩm hữu cơ có liên quan đáng kể đến cả khía cạnh thái độ vị lợi và hưởng thụ. Theo đó, các giả thuyết $\mathrm{H} 3 \mathrm{a}$ và $\mathrm{H} 3 \mathrm{~b}$ có thể được phát biểu như sau:

H3a: Nhận thức của nguời tiêu dùng về thuộc tính Bảo vệ hệ sinh thái có một tác động đáng kể đối với Thái độ vị lợi hướng tới việc mua thực phẩm hũu co:

H3b: Nhận thức của nguời tiêu dùng về thuộc tính Bảo vệ hệ sinh thái có một tác động đáng kể đối với Thái độ hưởng thu hướng tới việc mua thực phẩm hũu co.

Sự hẩp dẫn giác quan đối với thái độ hưởng thụ: Các thuộc tính cảm quan có liên quan đến sự xuất hiện, mùi, và vị giác của thực phẩm. Từ lâu đã nhận ra rằng thuộc tính cảm giác là một trong những yếu tố quan trọng nhất mà người tiêu dùng đưa ra khi lựa chọn thực phẩm của mình [35]. Một số nhà nghiên cứu cũng nhận thấy hương vị hoặc các đặc tính cảm quan là động lực quan trọng trong việc mua thực phẩm hữu cơ [21]. Ảnh hưởng cảm xúc/kinh nghiệm của người tiêu dùng dường như được kích thích bởi thuộc tính cảm quan của thực phẩm hữu cơ, và do đó các đánh giá của họ sẽ được thực hiện chủ yếu dựa trên giá trị cảm xúc. Một số nghiên cứu cho thấy các thuộc tính cảm quan của thực phẩm hữu cơ như vị, màu sắc, và kết cấu được liên kết với sự bảo đảm, chủ nghĩa cảm quan, hưởng thụ và hạnh phúc [29, $32,34]$. Theo đó, giả thuyết $\mathrm{H} 4$ có thể được phát biểu như sau:

H4: Nhận thức của người tiêu dùng về thuộc tính Sụ hấp dẫn giác quan có một tác động tích cực đáng kể đối với Thái độ hưởng thu hướng tới việc mua thực phẩm hữu co.

Giá đối với thái độ vị lọ̣i và thái độ hưởng thụ: Theo lý thuyết kinh tế truyền thống, giá được xem như một sự hy sinh về tiền tệ cần thiết để mua hàng. Do đó, giá cao hơn sẽ nâng cao nhận thức về chi phí kinh tế và do đó ảnh hưởng tiêu cực đến việc đánh giá sản phẩm và các ý định mua hàng [25]. Vai trò của giá như một biện pháp hy sinh dường như là một quan điểm phổ biến trong việc mua thực phẩm hữu cơ, có lẽ do niềm tin rằng thức ăn hữu cơ rất đắt [29]. Do đó, giá cao được xem là một trở ngại lớn đối với việc mua thực phẩm hữu cơ [21]. Do đó, nhận thức về giá thực phẩm hữu cơ càng cao thì thái độ với việc mua thực phẩm hữu cơ ít tích cực hơn. Hơn nữa, chúng tôi cho rằng nhận thức về giá có liên quan đến cả hai thái độ vị lợi và hưởng thụ bởi vì giá dường như là một nguồn lợi ích cả về thực tế và cảm xúc [36]. Các nhà nghiên cứu đã tìm thấy rằng cả hai phản ứng vị lợi và hưởng thụ đã được gợi ra từ người mua sắm thông qua việc trả tiền Một mức giá thấp hoặc tiết kiệm giá cả. Trong khi tiện ích kinh tế phát sinh từ tiết kiệm giá đã dẫn đến những phản ứng có lợi, giá thấp cũng dẫn đến các phản ứng cảm tính như một 


\section{CỦA NGƯỜI TIÊU DÙNG THÀNH PHỐ HỒ CHÍ MINH DỬA TRÊN MÔ HİNH S-O-R}

cảm giác hưng phấn, đạt thành tựu và niềm tự hào [36]. Theo đó, các giả thuyết H5a và H5b có thể được phát biểu như sau:

H5a: Nhận thức của người tiêu dùng về thuộc tính Giá có một tác động tiêu cực đáng kể đối với Thái độ vị lợ huớng tới việc mua thực phẩm hũu co.

H5b: Nhận thức của người tiêu dùng về thuộc tính Giá có một tác động tiêu cưcc đáng kể đối với Thái độ hưởng thu hướng tới việc mua thực phẩm hữu co.

Thái độ vị lọ̣i và thái độ hưởng thụ đối với dụ̣ định mua sản phẩm hữu co: Nhiều nghiên cứu đã tìm ra một mối quan hệ tích cực giữa thái độ người tiêu dùng với ý định mua hàng và/hoặc hành vi mua hàng [11]. Do đó, người tiêu dùng có thái độ thích hợp đối với việc mua thực phẩm hữu cơ nhiều khả năng sẽ chứng minh ý định mua hàng hành vi. Theo đó, các giả thuyết H6a và H6b có thể được phát biểu như sau:

H6a: Thái độ vị lợi của người tiêu dùng có một tác động tích cực đáng kể đối với Dự định mua thực phẩm hũu co:

H6b: Thái độ hưởng thu của người tiêu dùng có một tác động tích cục đáng kể đối với Dụ định mua thực phẩm hữu co:

\subsection{Mô hình nghiên cứu}

Với 11 giả thuyết được hình thành và biện luận ở trên, mô hình nghiên cứu được xây dựng như trong Hình 1.

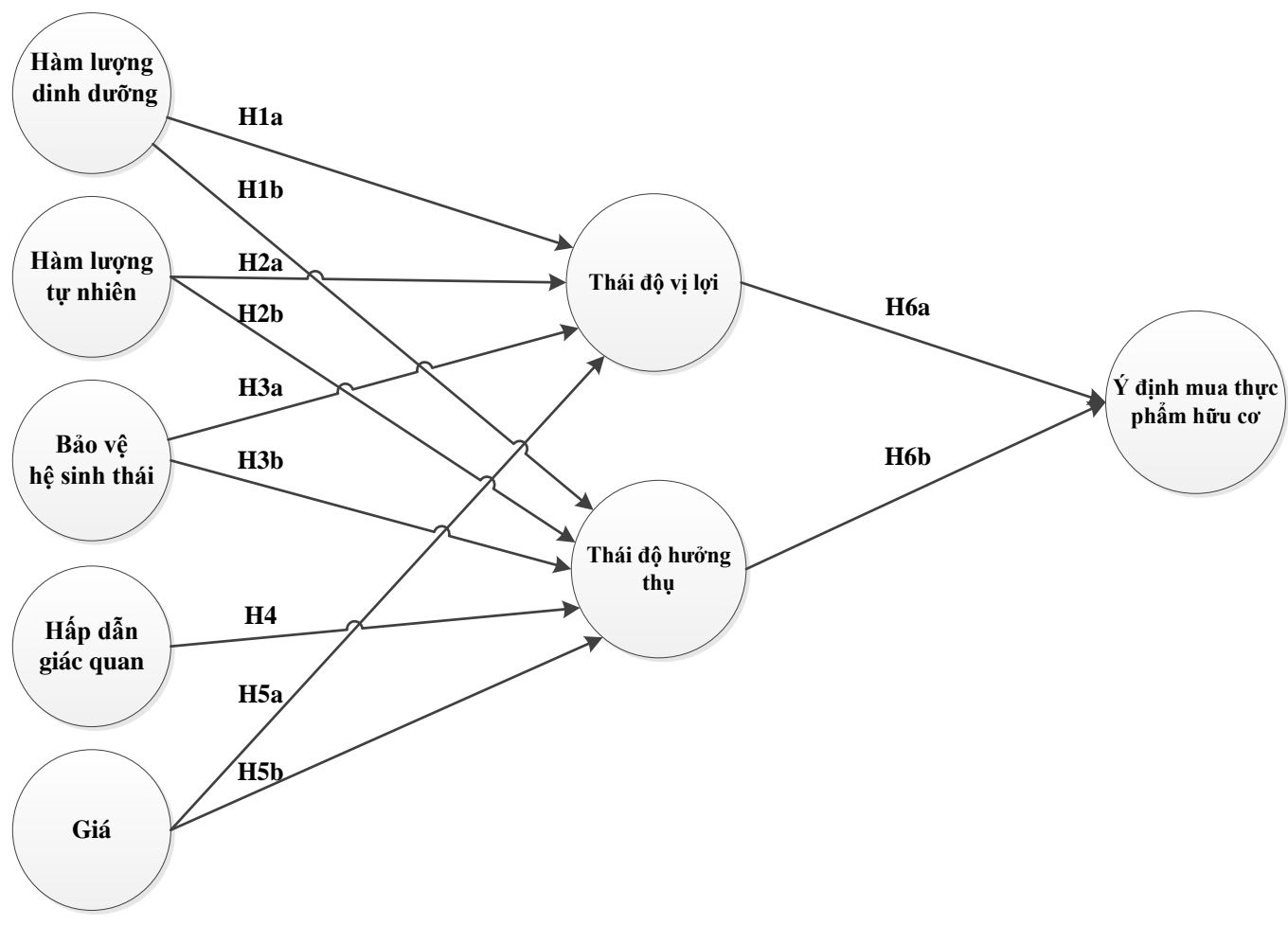

Hình 1. Mô hình nghiên cứu đề xuất

\section{PHƯƠNG PHÁP NGHIÊN CÚU}

Mô hình và các giả thuyết được kiểm định dựa trên bộ dữ liệu có kích thước 289 mẫu. Mẫu được thu thập qua một cuộc khảo sát theo phương pháp lấy mẫu thuận tiện tại Tp. Hồ Chí Minh. Đối tượng khảo sát là những người tiêu dùng Việt Nam có độ tuổi từ 20 tuổi trở lên đã sử dụng các thực phẩm hữu cơ. Phương pháp tiếp cận là phỏng vấn trực tiếp tại những cửa hàng bán các thực phẩm hữu cơ và các nơi thuận tiện khác như trường học, tại nhà và nơi làm việc.

Nội dung các thang đo đều được kế thừa từ nghiên cứu Lee [24], có hiệu chỉnh và bổ sung thông qua bước phỏng vấn sơ bộ định tính, cụ thể có bổ sung 1 biến quan sát trong thang đo Giá (xem Bảng 2). Theo đó, thang đo Hàm lượng dinh dưỡng có 4 biển quán sát, thang đo Hàm lượng tự nhiên có 3 biến 
quan sát, thang đo Bảo vệ hệ sinh thái có 4 biến quan sát, thang đo Sự hấp dẫn giác quan có 3 biến quan sát, thang đo Giá có 3 biến quan sát, thang đo Thái độ vị lợi có 4 biến quan sát, thang đo Thái độ hưởng thụ có 4 biến quan sát và thang đo Ý định mua thực phẩm hữu cơ có 3 biến quan sát. Các thang đo có dạng Likert 5 điểm.

\section{KẾT QUẢ}

\subsection{Mô tả mẫu}

Như trình bày trong Bảng 1, mẫu dữ liệu được thu thập từ 289 người tiêu dùng đã sử dụng thực phẩm hữu cơ tại Tp. Hồ Chí Minh. Đa số những người tiêu dùng tham gia khảo sát là Nữ $(64,71 \%)$ và đã kết hôn $(70,24 \%)$ có độ tuổi chủ yếu nằm trong khoảng 26-35 (32,18\%) và 36-45 (29,80\%). Trình độ học vấn của những người được khảo sát thì Đại học chiếm đa số $(47,06 \%)$ và thu nhập hàng tháng của họ chủ yếu nằm trong khoảng trên 10 triệu đến 20 triệu $\mathrm{VNĐ}(37,02 \%)$.

Bảng 1. Mô tả mẫu $(\mathrm{n}=289)$

\begin{tabular}{|c|c|c|c|c|c|}
\hline Giới tính & Tần số & Tỷ lệ \% & Học vấn & Tần số & Tỷ lệ \% \\
\hline Nam & 102 & 35,29 & Phổ thông & 25 & 8,65 \\
\hline Nũ̃ & 187 & 64,71 & Trung Cấp/Cao đẳng & 43 & 14,88 \\
\hline Tổng & 289 & 100 & Đại học & 136 & 47,06 \\
\hline Độ tuổi & Tần số & Tỷ lệ \% & Sau đại học & 85 & 29,41 \\
\hline 20-25 tuổi & 28 & 9,69 & Tổng & 289 & 100 \\
\hline 26-35tuổi & 93 & 32,18 & Thu nhập hàng tháng & Tần số & Tỷ lệ \% \\
\hline 36-45tuổi & 115 & 39,8 & < 5 triệu VNĐ & 27 & 9,34 \\
\hline 45 tuổi trở lên & 53 & 18,33 & $5-\leq 10$ triệu VNĐ & 84 & 29,07 \\
\hline Tổng & 289 & 100 & $10-\leq 20$ triệu VNĐ & 107 & 37,02 \\
\hline Tình trạng hôn nhân & Tần số & Tỷ lệ \% & $\geq 20$ triệu VNĐ & 71 & 24,57 \\
\hline Độc thân & 86 & 29,76 & Tổng & 289 & 100 \\
\hline Đã kết hôn & 203 & 70,24 & & & \\
\hline Tổng & 289 & 100 & & & \\
\hline
\end{tabular}

\section{2 Đánh giá và gạn lọc thang đo}

Các thang đo được đánh giá sơ bộ bằng phân tích nhân tố khám phá (EFA) và độ tin cậy Cronbach's Alpha. Kết quả đánh giá độ tin cậy cho thấy tất cả các thang đo đều có hệ số Cronbach's Alpha từ 0,827 đến 0,897 lớn hơn 0,7 và các hệ số tương quan biến-tổng từ 0,307 đến 0,833 nhỏ hơn 0,3 nên các thang đo này đều đạt độ tin cậy. Còn kết quả phân tích nhân tố khám phá (EFF) với 28 biến quan sát quan ban đầu, đã loại một biến (xem Bảng 2) do có hệ số tải nhân tố nhỏ hơn 0,5. Các thang đo với 27 biến còn lại sẽ được đưa vào phân tích nhân tố khẳng định (CFA).

Kết quả kiểm định mô hình đo lường cho thấy mô hình đo lường này có 296 bậc tự do, giá trị Chisquare bằng 385,973 , Chi-square/df bằng 1,304 nhỏ hơn $2, \mathrm{p}$ bằng 0,000 nhỏ hơn 0,05 ; tuy nhiên GFI bằng 0,912 , TLI bằng 0,978 , CFI bằng 0,981 đều lớn hơn 0,9 và RMSEA bằng 0,032 nhỏ hơn 0,08 . Như vậy, có thể kết luận là mô hình này phù hợp với dữ liệu thu thập được từ thị trường.

Như thể hiện trên Bảng 2 , hệ số tải chuẩn hoá của các biến quan sát dao động từ 0,06 đến 0,963 lớn hơn 0,5 , đồng thời phương sai trích của các thang đo (AVE) từ 0,563 đến 0,776 lớn hơn 0,5 nên các thang đo đạt giá trị hội tụ. Độ tin cậy tổng hợp $(\mathrm{CR})$ của các thang đo từ 0,824 đến 0,927 lớn hơn 0,7 nên các thang đo đều đạt độ tin cậy. Tương quan giữa các khái niệm dao động từ 0,008 tới 0,394 thấp đáng kể với $1(\mathrm{p}=0,05)$ nên các thang đo đều đạt độ giá trị phân biệt. 
Bảng 2. Kết quả đánh giá thang đo

\begin{tabular}{|c|c|}
\hline Thang đo và biến quan sát & $\begin{array}{l}\text { Hệ số tải } \\
\text { chuẩn hóa }\end{array}$ \\
\hline \multicolumn{2}{|l|}{ Hàm lượng dinh dưỡng: Cronbach's Alpha = 0,876; CR = 0,886; AVE = 0,664 } \\
\hline Thực phẩm hữu cơ chứa nhiều vitamin và khoáng chất & 0,829 \\
\hline Thực phẩm hữu cơ giữ cho tôi được khỏe mạnh & 0,644 \\
\hline Thực phẩm hữu cơ bổ dưỡng & 0,846 \\
\hline Thực phẩm hữu cơ có hàm lượng Protein cao & 0,886 \\
\hline \multicolumn{2}{|l|}{ Bảo vệ hệ sinh thái: Cronbach's Alpha = 0,848; CR = 0,828; AVE = 0,616 } \\
\hline Thực phẩm hữu cơ được sản xuất bằng cách mà không làm mất đi sự cân bằng của tự nhiên & 0,915 \\
\hline Thực phẩm hữu cơ được đóng gói theo cách thân thiện với môi trường & 0,907 \\
\hline Thực phẩm hữu cơ được sản xuất bằng cách mà động vật không phải trải qua đau đớn & 0,910 \\
\hline Thực phẩm hữu cơ được sản xuất bằng cách mà động vật không phải trải qua đau đớn & $* *$ \\
\hline \multicolumn{2}{|l|}{ Thái độ vị lợi: Cronbach's Alpha = 0,897; CR = 0,927; AVE = 0,761 } \\
\hline Thực phẩm hữu cơ là hiệu quả & 0,874 \\
\hline Thực phẩm hữu cơ là có ích & 0,835 \\
\hline Thực phẩm hữu cơ thiết thực & 0,821 \\
\hline Thực phẩm hữu cơ là cần thiết & 0,816 \\
\hline \multicolumn{2}{|l|}{ Thái độ hưởng thụ: Cronbach's Alpha $=0,846 ; \mathrm{CR}=0,852 ; \mathrm{AVE}=0,591$} \\
\hline Thực phẩm hữu cơ làm tôi thấy vui & 0,785 \\
\hline Thực phẩm hữu cơ làm tôi kích thích & 0,796 \\
\hline Thực phẩm hữu cơ làm tôi cảm thấy thú vị & 0,770 \\
\hline Thực phẩm hữu cơ làm tôi cảm thấy phấn khích & 0,697 \\
\hline \multicolumn{2}{|l|}{ Ý định hành vi mua: Cronbach's Alpha $=0,875 ; \mathrm{CR}=0,860 ; \mathrm{AVE}=0,563$} \\
\hline Nếu tôi phải mua trở lại, tôi sẽ mua thực phẩm hữu cơ & 0,823 \\
\hline Tôi cố gắng mua thực phẩm hữu cơ vì nó là lựa chọn tốt nhất đối với tôi & 0,886 \\
\hline Tôi tự xem tôi là khách hàng quen thuộc, trung thành của thực phẩm hữu cơ & 0,808 \\
\hline \multicolumn{2}{|l|}{ Hàm lượng tự nhiên: Cronbach's Alpha = 0,853; CR = 0,886; AVE = 0,728 } \\
\hline Thực phẩm hữu cơ không chưa chất phụ gia & 0,879 \\
\hline Thực phẩm hữu cơ chứa những thành phần tự nhiên & 0,963 \\
\hline Thực phẩm hữu cơ không chứa những chất nhân tạo & 0,606 \\
\hline \multicolumn{2}{|l|}{ Giá: Cronbach's Alpha $=0,829 ; \mathrm{CR}=0,910 ; \mathrm{AVE}=0,776$} \\
\hline Thực phẩm hữu cơ đắt tiền & 0,630 \\
\hline Giá của thực phẩm hữu cơ là cao & 0,829 \\
\hline Thực phẩm hữu cơ đáng đồng tiền $(*)$ & 0,914 \\
\hline \multicolumn{2}{|l|}{ Hấp dẫn giác quan: Cronbach's Alpha $=0,827 ; \mathrm{CR}=0,824 ; \mathrm{AVE}=0,610$} \\
\hline Thực phẩm hữu cơ trông đẹp mắt & 0,760 \\
\hline Thực phẩm hữu cơ vừa vặn và đồng đều & 0,809 \\
\hline Thực phẩm hữu cơ có vị ngon & 0,784 \\
\hline
\end{tabular}

Ghi chú: *: Biến quan sát được bổ sung thông qua phỏng vấn định tính; **: Biến quan sát bị loại trong phân tích nhân tố khám phá (EFA).

\subsection{Kiểm định mô hình cấu trúc tuyến tính}

Kết quả kiểm định mô hình cấu trúc tuyến tính cho thấy mô hình lý thuyết này có 303 bậc tự do, giá trị Chi-square bằng 440,417, Chi-square/df bằng 1,454 nhỏ hơn $2, \mathrm{p}$ bằng 0,000 nhỏ hơn 0,05 ; tuy nhiên GFI bằng 0,900 , TLI bằng 0,967 , CFI bằng 0,971 đều lớn hơn hoặc bằng 0,9 và RMSEA bằng 0,040 nhỏ hơn 0,08 . Như vậy, có thể kết luận là mô hình này phù hợp với dữ liệu thu thập được từ thị trường. 
Bảng 3. Kết quả kiểm định mô hình cấu trúc tuyến tính

\begin{tabular}{|c|c|c|c|}
\hline Mối quan hệ & $\begin{array}{c}\text { Trọng số hồi quy } \\
\text { chuẩn hóa }\end{array}$ & $\mathbf{p}$ & $\begin{array}{c}\text { Kiểm định giả } \\
\text { thuyết }\end{array}$ \\
\hline Hàm lượng dinh dưỡng $\rightarrow$ Thái độ vị lợi & 0,304 & 0,002 & Ủng hộ H1a \\
\hline Hàm lượng dinh dưỡng $\rightarrow$ Thái độ hưởng thụ & 0,259 & 0,003 & Ủng hộ H1b \\
\hline Hàm lượng tự nhiên $\rightarrow$ Thái độ vị lợi & 0,178 & 0,002 & Ủng hộ H2a \\
\hline Hàm lượng tự nhiên $\rightarrow$ Thái độ hưởng thụ & 0,179 & 0,016 & Ủng hộ H2b \\
\hline Bảo vệ hệ sinh thái $\rightarrow$ Thái độ vị lợi & 0,200 & 0,004 & Ủng hộ H3a \\
\hline Bảo vệ hệ sinh thái $\rightarrow$ Thái độ hưởng thụ & 0,163 & 0,012 & Ủng hộ H3b \\
\hline Hấp dẫn giác quan $\rightarrow$ Thái độ hưởng thụ & 0,204 & 0,006 & Ủng hộ H4 \\
\hline Giá $\rightarrow$ Thái độ vị lợi & $-0,420$ & 0,002 & Ủng hộ H5a \\
\hline Giá $\rightarrow$ Thái độ hưởng thụ & $-0,305$ & 0,003 & Ủng hộ H5b \\
\hline Thái độ vị lợi $\rightarrow$ Ý định mua & 0,398 & 0,002 & Ủng hộ H6a \\
\hline Thái độ hưởng thụ $\rightarrow$ Ý định mua & 0,406 & 0,002 & Ủng hộ H6b \\
\hline
\end{tabular}

\section{THẢO LUẬN KẾT QUẢ}

Trong 5 yếu tố tác động trực tiếp lên Thái độ vị lợi và Thái độ hưởng thụ thì yếu tố Giá có tác động tiêu cực lớn nhất với trọng số hồi quy chuẩn hóa lần lượt là $\beta=-0,420$ và $\beta=-0,305$, điều này cho thấy yếu tố Giá vẫn là rào cản chính trong việc hình thành ý định mua thực phẩm hữu cơ của người tiêu dùng Việt Nam.

Còn yếu tố Hàm lượng dinh dưỡng là yếu tố có tác động tích trực tiếp lớn nhất lên Thái độ vị lợi $(\beta=$ $0,304)$ và Thái độ hưởng thụ $(\beta=0,259)$, điều này cho thấy người tiêu dùng Việt Nam vẫn quan tâm hàng đầu đối với những hàm lượng dinh dưỡng có trong thực phẩm hữu cơ.

Yếu tố Hấp dẫn giác quan chỉ có tác động trực tiếp tích cực và mạnh thứ nhì lên Thái độ hưởng thụ ( $\beta=$ $0,204)$, điều này cho thấy ngoài các thành phần dinh dưỡng có trong thực phẩm hữu cơ thì người tiêu dùng còn quan tâm đến vấn đề về trực quan đối với các thực phẩm hữu cơ.

Còn hai yếu tố còn lại là Hàm lượng tự nhiên và Bảo vệ hệ sinh thái có tác động trực tiếp và tích cực lên yếu tố Thái độ vị lợi và Thái độ hưởng thụ, điều này cho thấy người tiêu dùng Việt Nam cũng rất quan tâm đến vấn đề các thành phần tự nhiên có trong thực phẩm hữu cơ và song song đó là phải bảo vệ được hệ sinh thái.

Thái độ vị lợi $(\beta=0,398)$ và Thái độ hưởng thụ $(\beta=0,406)$ có tác động trực tiếp đáng kể lên Ý định mua hàng. Kết quả này cho thấy rằng ngoài việc sử dụng các đánh giá về lý trí người tiêu dùng còn chú ý tới yếu tố liên quan đến cảm xúc và giác quan để dẫn tới quyết định mua hàng.

Kết quả có được từ nghiên cứu này sẽ phần nào giúp cho những người làm tiếp thị hiểu rõ được tác động của các yếu tố lên ý định mua thực phẩm hữu cơ, để từ đó họ có thể thực hiện các chiến lược kinh doanh nói chung và các chiến lược tiếp thị nói riêng để thúc đẩy quyết định mua thực phẩm hữu cơ của người tiêu dùng Việt Nam. Một số hàm ý quan trọng cho các nhà bán lẻ thực phẩm hữu cơ có thể được rút ra từ nghiên cứu này, bao gồm thực hành tiếp thị. Bên cạnh đó với việc sử dụng mô hình $\mathrm{S}-\mathrm{O}-\mathrm{R}$ được hiệu chỉnh, nghiên cứu này cung cấp sự hỗ trợ lý thuyết cho nghiên cứu về ý định mua thực phẩm hữu cơ tại Việt Nam.

\section{KẾT LUẬN}

Để đáp ứng một cách hiệu quả sự tăng trưởng liên tục của thị trường thực phẩm hữu cơ, các công ty cần phải xác định được các thuộc tính mang lại cho thực phẩm hữu cơ lợi thế hơn thực phẩm thông thường và để hiểu cách thức người tiêu dùng định hình ý định mua thực phẩm hữu cơ. Các công ty cụ thể là những người làm tiếp thị và những người làm chính sách trong việc lập chiến lược kinh doanh và chiến lược tiếp thị hợp lý cần lưu ý những điểm sau:

- Yếu tố thái độ hưởng thụ hình thành nhờ nhận thức về các yếu tố Hấp dẫn giác quan, Bảo vệ hệ sinh thái, Giá, Hàm lượng dinh dưỡng, Hàm lượng tự nhiên giúp phát triển ý định mua thực phẩm hữu cơ. Nếu người tiêu dùng đánh giá các thuộc tính cảm quan của thực phẩm hữu cơ là dễ chịu, trước hoặc sau 
khi tiêu dùng, họ có thể sẽ mua thực phẩm hữu cơ. Vì vậy, tại các điểm phân phối thực phẩm hữu cơ trực tiếp đến người tiêu dùng thì nên tập trung vào khía cạnh tạo ra các tín hiệu tích cực về thị giác và xúc giác để kích thích cảm quan của người tiêu dùng. Ví dụ như các hình ảnh, video quảng cáo bắt mắt được đặt ở vị trí thuận tiện cho khách hàng dễ tiếp cận. Tùy theo sản phẩm mà các cửa hàng phân phối có thể bố trí thực phẩm hữu cơ sao cho người tiêu dùng có thể tiếp cận trực tiếp bằng các giác quan của họ bằng cách chạm vào, cầm trên tay, nếm thử,... các sản phẩm hữu cơ.

- Thái độ vị lợi có tác động tương đương với thái độ hưởng thụ lên quyết định mua thực phẩm hữu cơ của người dùng. Ở khía cạnh này, quyết định mua của người tiêu dùng dựa trên các phân tích mang tính lý trí, vì vậy để tăng nhận thức của người tiêu dùng về thực phẩm hữu cơ và giảm mức độ không chắc chắn của người tiêu dùng về các đặc tính đáng tin cậy của thực phẩm hữu cơ. Các nhà phân phối và nhà sản xuất có thể giúp người tiêu dùng phát triển nhận thức tích cực hơn về thực phẩm hữu cơ bằng cách cải thiện khả năng truy xuất thông tin và nguồn gốc xuất xứ của sản phẩm, đồng thời cung cấp đầy đủ các giấy chứng nhận về tiêu chuẩn sản xuất thực phẩm hữu cơ và bằng chứng khách quan về nội dung dinh dưỡng và quá trình sản xuất thực phẩm hữu cơ (như tem truy xuất nguồn gốc xuất xứ, nhãn thông tin dinh dưỡng, các chứng nhận của các tổ chức như USDA (chứng nhận hữu cơ theo tiêu chuẩn Mỹ),...). Thông điệp quảng cáo có thể tập trung vào những lợi ích cá nhân (như sức khoẻ và dinh dưỡng) và lợi ích xã hội (như thân thiện với môi trường và bảo vệ hệ sinh thái) nhằm tạo niềm tin và sự tin tưởng của người tiêu dùng đối với thực phẩm hữu cơ. Những người làm về tiếp thị có thể thiết kế các chiến dịch truyền thông được thiết kế cụ thể để thông báo cho khách hàng về những lợi ích về sức khoẻ, môi trường và đạo đức của sản phẩm thực phẩm và phân phối các tờ rơi tại các điểm bán lẻ.

- Yếu tố giá có ảnh hưởng tiêu cực đến thái độ nhận thức của người tiêu dùng và có tác động lớn đến dự định mua của người tiêu dùng. Vì vậy, các nhà phân phối thực phẩm hữu cơ phải xác định được lợi ích quan trọng của thực phẩm hữu cơ và làm nổi bật những lợi ích này lên so với thực phẩm thông thường, đồng thời phải chứng minh rằng nó rất đáng giá (các nhà phân phối có thể quảng cáo thực phẩm hữu cơ đảm bảo sức khỏe cho người tiêu dùng, không gây ngộ độc và không chứa các chất gây ung thư). Ngoài ra, các nhà tiếp thị cũng như các nhà phân phối thực phẩm hữu cơ phải truyền tải được những thông điệp về việc góp phần bảo vệ môi trường và hệ sinh thái bền vững của thực phẩm hữu cơ đến người tiêu dùng.

Cũng như các nghiên cứu khác, nghiên cứu này cũng có một số hạn chế sau. Trước tiên, nghiên cứu sử dụng phương pháp lấy mẫu thuận tiện nên có thể dữ liệu thu thập được có độ tin cậy chưa cao; vì vậy, các nghiên cứu trong tương lai có thể sử dụng các phương pháp lấy mẫu xác suất để tăng độ tin cậy của mẫu hơn. Cuối cùng, nghiên cứu chỉ thực hiện trên địa bàn thành phố Hồ Chí Minh; vì vậy, các nghiên cứu tiếp theo có thể xem xét thực hiện nhiều địa phương hơn hoặc trong phạm vi toàn Việt Nam.

\section{TÀI LIẸU THAM KHẢO}

[1] P. Moustier, M. Figuié, N. T. T. Loc, and H. T. Son, The role of coordination in the safe and organic vegetable chains supplying Hanoi, in International Symposium on Improving the Performance of Supply Chains in the Transitional Economies, 2005, vol. 699, pp. 297-306.

[2] H. V. Khai, Assessing Consumer Preferences for Organic Vegetables: A Case Study in the Mekong Delta, Vietnam, Information Management and Business Review, vol. 7, no. 1, pp. 41-47, 2015.

[3] E. Tsakiridou, C. Boutsouki, Y. Zotos, and K. Mattas, Attitudes and behaviour towards organic products: an exploratory study, International Journal of Retail \& Distribution Management, vol. 36, no. 2, pp. 158-175, 2008.

[4] Nielsen. (2016) Chỉ số niềm tin người tiêu dùng giữ ổn định trong quý 03/2016 [Online]. Available: http://www.nielsen.com/vn/vi/insights/2016/vietnam-cci-q2-20161.html.

[5] M. J. Lord and P. Tangtrongjita. (2011) Mapping the Organic Vegetable Value Chain along the East West Economic Corridor [Online]. Available: https://mpra.ub.uni-muenchen.de/41145/. 
[6] J. P. Reganold and J. M. Wachter, Organic agriculture in the twenty-first century, Nature Plants, vol. 2, pp. 18, 2016.

[7] A. Tarkiainen and S. Sundqvist, Subjective norms, attitudes and intentions of Finnish consumers in buying organic food, British Food Journal, vol. 107, no. 11, pp. 808-822, 2005.

[8] M. F. Chen, Consumer attitudes and purchase intentions in relation to organic foods in Taiwan: Moderating effects of food-related personality traits, Food Quality and Preference, vol. 18, no. 7, pp. 1008-1021, 2007.

[9] L. Zagata, Consumers' beliefs and behavioural intentions towards organic food. Evidence from the Czech Republic, Appetite, vol. 59, no. 1, pp. 81-89, 2012.

[10] M. Fishbein and I. Ajzen, Belief, attitude, intention and behavior: An introduction to theory and research. Addison-Wesley, 1975.

[11] I. Ajzen and M. Fishbein, Understanding attitudes and predicting social behaviour. Prentice-Hall, 1980.

[12] M. Conner and C. J. Armitage, Extending the theory of planned behavior: A review and avenues for further research, Journal of Applied Social Psychology, vol. 28, no. 15, pp. 1429-1464, 1998.

[13] A. Mehrabian and J. A. Russell, An approach to environmental psychology. MIT Press, 1974.

[14] H. J. Lee and Z. S. Yun, Consumers' perceptions of organic food attributes and cognitive and affective attitudes as determinants of their purchase intentions toward organic food, Food Quality and Preference, vol. 39, pp. 259-267, 2015.

[15] M. F. Chen, Consumer attitudes and purchase intentions in relation to organic foods in Taiwan: Moderating effects of food-related personality traits, Food Quality and Preference, vol. 18, no. 7, pp. 1008-1021, 2007.

[16] L. H. Essoussi and M. Zahaf, Decision making process of community organic food consumers: an exploratory study, Journal of Consumer Marketing, vol. 25, no. 2, pp. 95-104, 2008.

[17] I. Ajzen, The Theory of Planned Behavior, Organizational Behavior and Human Decision Processes, vol. 50, pp. 179-211, 1991.

[18] Dr. Mazourkik, Dinh duõ̃ng trục quan. Nhà xuất bản Y học, 2009.

[19] M. Lindeman and M. Väänänen, Measurement of ethical food choice motives, Appetite, vol. 34, pp. 55-59, 2000.

[20] G. C. Harper and A. Makatouni, Consumer perception of organic food production and farm animal welfare, British Food Journal, vol. 104, no. 5, pp. 287-299, 2002.

[21] M. K. Magnusson, A. Arvola, U. K. K. Hursti, L. Åberg, and P. O. Sjödén, Choice of organic foods is related to perceived consequences for human health and to environmentally friendly behaviour, Appetite, vol. 40, no. 2, pp. 109-117, 2003.

[22] S. Lockie, K. Lyons, G. Lawrence, and J. Grice, Choosing organics: A path analysis of factors underlying the selection of organic food among Australian consumers, Appetite, vol. 43, no. 2, pp. 135-146, 2004.

[23] D. R. Lichtenstein, N. M. Ridgway, and R. G. Netemeyer, Price perceptions and consumer shopping behavior: a field study, Journal of Marketing Research, vol. 30, no. 2, pp. 234-245, 1993.

[24] D. B. S. H. E. Lee, The relationship between price and objective apprarel quality: A comparison between the United States market and Korean market (Master's thesis). Texas Tech University, 1996.

[25] A. R. Rao and K. B. Monroe, The moderating effect of prior knowledge on cue utilization in product evaluations, Journal of consumer research, vol. 15, no. 2, pp. 253-264, 1988. 
[26] R. Batra and O. T. Ahtola, Measuring the hedonic and utilitarian sources of consumer attitudes, Marketing Letters, vol. 2, no. 2, pp. 159-170, 1991.

[27] K. E. Voss, E. R. Spangenberg, and B. Grohmann, Measuring the hedonic and utilitarian dimensions of consumer attitude, Journal of Marketing Research, vol. 40, no. 3, pp. 310-320, 2003.

[28] D. Gursoy, E. R. Spangenberg, and D. G. Rutherford, The hedonic and utilitarian dimensions of attendees' attitudes toward festivals, Journal of Hospitality \& Tourism Research, vol. 30, no. 3, pp. 279-294, 2006.

[29] S. Padel and C. Foster, Exploring the gap between attitudes and behaviour: Understanding why consumers buy or do not buy organic food, British Food Journal, vol. 107, no. 8, pp. 606-625, 2005.

[30] E. Lea and T. Worsley, Australians' organic food beliefs, demographics and values, British Food Journal, vol. 107, no. 11, pp. 855-869, 2005.

[31] A. Davies, A. J. Titterington, and C. Cochrane, Who buys organic food? A profile of the purchasers of organic food in Northern Ireland, British Food Journal, vol. 97, no. 10, pp. 17-23, 1995.

[32] C. Fotopoulos, A. Krystallis, and M. Ness, Wine produced by organic grapes in Greece: Using means-end chains analysis to reveal organic buyers' purchasing motives in comparison to the non-buyers, Food Quality and Preference, vol. 14, no. 7, pp. 549-566, 2003.

[33] B. Aarset, S. Beckmann, E. Bigne, M. Beveridge, T. Bjorndal, J. Bunting, and L. Reisch, The European consumers' understanding and perceptions of the "organic" food regime: The case of aquaculture, British Food Journal, vol. 106, no. 2, pp. 93-105, 2004.

[34] R. Zanoli and S. Naspetti, Consumer motivations in the purchase of organic food: A means-end approach, British Food Journal, vol. 104, no. 8, pp. 643-653, 2002.

[35] A. Steptoe, M. P. Tessa, and W. Wardle, Development of a measure of the motives underlying the selection of food: the food choice questionnaire, Appetite, vol. 25, no. 3, pp. 267-284, 1995.

[36] H. Mano and M. T. Elliott, Smart shopping: The origins and consequences of price savings, in Advances in Consumer Research, 1997, vol. 24, pp. 504-510.

Ngày nhận bài: 17/11/2017

Ngày chấp nhận đăng: 15/02/2018 